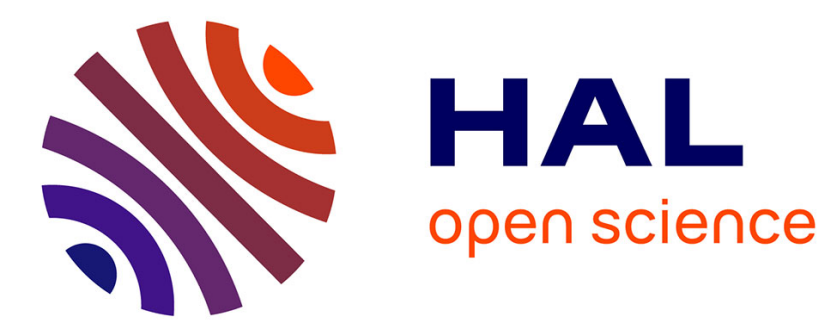

\title{
Priming motivation through unattended speech
}

Rémi Radel, Philippe Sarrazin, Marie Jehu, Luc Pelletier

\section{To cite this version:}

Rémi Radel, Philippe Sarrazin, Marie Jehu, Luc Pelletier. Priming motivation through unattended speech. British Journal of Social Psychology, 2013, 52 (4), pp.763-772. 10.1111/bjso.12030 . hal00947433

\section{HAL Id: hal-00947433 \\ https://hal.science/hal-00947433}

Submitted on 17 Feb 2014

HAL is a multi-disciplinary open access archive for the deposit and dissemination of scientific research documents, whether they are published or not. The documents may come from teaching and research institutions in France or abroad, or from public or private research centers.
L'archive ouverte pluridisciplinaire HAL, est destinée au dépôt et à la diffusion de documents scientifiques de niveau recherche, publiés ou non, émanant des établissements d'enseignement et de recherche français ou étrangers, des laboratoires publics ou privés. 
Running head: UNATTENDED PRIMING OF MOTIVATION

\section{Priming Motivation Through Unattended Speech}

Rémi Radel ${ }^{1,2 \star}$, Philippe Sarrazin ${ }^{2}$, Marie Jehu $^{1}$, \& Luc Pelletier $^{1}$

${ }^{1}$ School of Psychology, University of Ottawa, Canada

${ }^{2}$ Laboratoire SENS, Joseph Fourier University, Grenoble 1, France

British Journal of Social Psychology (2013), N52, PP. 763-772

DOI: $10.1111 /$ bjso. 12030

Word count (exc. figures/tables): 5699

${ }^{*}$ Requests for reprints should be addressed to Rémi Radel, Laboratoire LAMHESS, University of Nice Sophia-Antipolis, 261 route de Grenoble, 06205 Nice Cedex 3, France. E-mail:

remi.radel@gmail.com. 


\section{Abstract}

This paper examines whether motivation can be primed through unattended speech. Study 1 tested this question using a dichotic listening paradigm and repeated strength measures. In comparison to the baseline condition, in which the unattended channel was only composed by neutral words, the presence of words related to high (low) intensity of motivation led participants to exert more (less) strength when squeezing a hand dynamometer. A second study provided a more realistic procedure. Participants could hear a barely audible conversation while focusing on a demanding task. Participants who were exposed to a conversation depicting intrinsic motivation performed better and persevered longer in a subsequent word fragment-completion task than those who were exposed to the same conversation made unintelligible. These findings indicate that motivation can be primed through the auditory modality even when attentional capacities are occupied.

keywords: motivation ; attention ; priming ; speech perception. 


\section{Priming Motivation through Unattended Speech}

Although the belief that motivation can originate from factors outside of the person's conscious control has existed for decades (Freud, 1920/1981; Maslow, 1948; McClelland, 1985), the lack of scientific evidence has led motivational theorists to propose models based only on reflective or controlled determinants of the action (e.g., Ajzen, 1991; Bandura, 1986; Locke \& Latham, 1990). However, numerous recent studies on this topic have yielded indisputable evidence that motivation can be the result of automatic processing as well (see Custers \& Aarts, 2010 for a review). But while an automatic process is not only characterized by its enfranchisement from consciousness (Bargh, 1994), this only characteristic has been investigated in the research on automatic processing of motivation. The aim of this paper is to examine if motivation could also be primed outside of the attentional focus.

\section{Automatic Activation of Motivation}

As suggested by Weiner's "god-like” metaphor (1992), the most influential motivational theories traditionally assumed that humans were all knowing, aware of their goals, and deliberated on their motivational state after thoughtful reflection on the costs and benefits of their actions. Since then, this idea has been challenged, and many studies have come to suggest that motivation could also result from automatic processes. For doing so, these studies have used a priming paradigm to show that motivational states can be activated outside of individuals' conscious awareness. Typically, these studies used a first task to prime the motivational state, then examined if participants' motivation was really affected by assessing several behavioral indices in a second task. The first study of this nature was conducted by Bargh and his colleagues (Bargh, Gollwitzer, Lee-Chai, Barndollar, \& Troetschel, 2001) who primed the goal to achieve 
using a scrambled sentence task. The participants who were exposed to words related to achievement during the scrambled sentence task (e.g. win or perform), performed better and persevered more in a second puzzle than those who were only exposed to neutral words. The goal to achieve was actually activated in the participants, as these outcomes are the typical consequences of the endorsement of this goal. Importantly, participants reported during the debriefing that the first task had no effect on their performance in the second task. Further studies have widely replicated goal priming effect using different methods of priming such as exposure to subliminal visual stimuli (e.g., Mitchell, Macrae, Schooler, Rowe, \& Milne, 2003), exposure to subtle environmental cues (e.g., Holland, Hendriks, \& Aarts, 2005), the perception of others' goals (e.g., Aarts, Hassin, \& Gollwitzer, 2004) and using different kinds of goals such as helping (Macrae \& Johnston, 1998), cleaning (Holland et al., 2005), memorizing (Mitchell et al., 2003), flirting or making money (Aarts et al., 2004). It should be noted that motivation priming is not simply limited to goals, since general motivational orientations such as extrinsic (i.e., doing an activity for separable consequences) versus intrinsic motivation (IM) (i.e., doing an activity for itself and the pleasure of doing it) have also been primed (e.g., Lévesque \& Pelletier, 2003; Radel, Sarrazin, Legrain, \& Gobancé, 2009a; Radel, Sarrazin, \& Pelletier, 2009b). For example, Radel et al. (2009b) demonstrated that when students were exposed to subliminal words related to IM (e.g., choice, interest) during a first cognitive task, they exerted more effort, persevered longer and performed better in learning a subsequent motor task than those who were primed with words related to extrinsic motivation (e.g., constraint, duty).

To rule out any hypotheses of conscious processing, a few recent studies have included an improved control measure of awareness consisting in an objective test (e.g., a 2-alternatives forced choice task) performed systematically trial after trial. Even when participants were 
objectively unaware of the primes, a motivation priming effect was still reported. For example, in the study by Aarts, Custer, and Marien (2008), the participants who were subliminally exposed to words related to a high intensity of motivation (e.g. vigorous) exerted more strength in squeezing a handgrip than participants who were not exposed to any subliminal words. It should be noted that an effect of unconscious motivation has even been imaged using fMRI (Pessiglione et al., 2007).

In conclusion, there is now ample evidence to support the fact that individuals' motivational state can result from automatic processing. However, as noted earlier, we only know that motivation can be activated outside of consciousness, while automatic processing can also be characterized by absence of intentionality, effort, and attention (Bargh, 1994; Schiffrin \& Schneider, 1977). For example, it is impossible to say if motivation could be primed in the absence of attention. This paper addressed this question by investigating if motivational cues embedded in unattended speech can prime the corresponding motivation.

\section{Unattended Speech Processing}

Since the first dichotic listening experiments by Cherry (1953), it has turned to be crucial to determine whether or not unattended speech is processed for designing models of attention and information processing (e.g., Broadbent, 1958; Deutsch \& Deutsch, 1963; Treisman, 1964; Posner, 1990). Research on the processing of unattended speech has stuck to the dichotic listening paradigm. In this paradigm, a different message is presented in each ear. Participants are asked to perform a demanding task with stimuli presented in one channel, while ignoring the other. The first support for unattended speech processing was provided by Moray (1959), who reported that participants are sometimes able to notice their name in an unattended channel of speech. This finding has been replicated by Wood and Cowan (1995a) who have also found that 
name detection led to a decrease in performance in the attended channel. Eich (1984) also provided support to the processing of unattended speech by using a priming procedure. While participants performed a shadowing task on the attended channel, a homophone and a word related to its less frequent meaning were presented in the unattended channel. Although participants were not able to recall the word pairs, they were more likely to give the homophone with the less frequent meaning when asked to spell it. This was congruent with results from the event related potential study by Bentin, Kutas, and Hillyard (1995), which indicated that while both attended and unattended words were semantically processed, attended words form traces that were subsequently more available to conscious recollection than unattended words.

Nevertheless, as reviewed by Holender (1986) and by Dupoux, Kouider, and Mehler (2003), the material used in all of these studies could have increased the likelihood of attentional switches. First, the unattended channel was comprised of isolated words that could easily capture attention (Holender, 1986). Second, the presentation rate of the stimuli in the attended channel was often slow, which likely caused attention to wander. As a result, a momentary attentional switch could occur and could lead participants to pick up some semantic information from the unattended channel. This might explain apparent results of unattended speech processing. Newstead and Dennis (1979) used continuous speech instead of isolated words in the unattended channel. By using this technique, the unattended speech had no influence on participants' interpretations of ambiguous sentences. In regards to the presentation rate of unattended stimuli, Wood, Stadler, and Cowan (1997) replicated Eich's (1984) implicit priming results using the same shadowing rate, but failed to replicate his findings with a faster rate.

In a set of studies using repetition priming, Dupoux et al. (2003) manipulated features of the unattended prime words and examined the response time to make a lexical decision on a 
target. In all of their studies, words were presented at a high rate in the attended channel, unattended speech was time compressed and was played $12 \mathrm{~dB}$ below the attended speech in order to reduce the probability of attentional switches. When the prime was embedded in a stream of speech with similar auditory properties, no priming effect was found. In addition, in situations where priming effects were found (e.g., isolated words in the unattended channel), most of the participants were aware of the presence of the prime.

While the processing of unattended speech was thought to be the result of a lack of control over attentional switches, a recent set of studies by Rivenez, Darwin, and Guillaume (2006) has challenged this view. Using a similar version of the priming procedure used by Dupoux et al. (2003), they examined the effect of a difference in fundamental frequency between the unattended and the attended speech. While prime words were embedded within continuous speech in the unattended channel, they sped up the detection of the same word in the attended channel, but only when the two messages differed in their fundamental frequency. In a further study, Rivenez et al. (2006, study 3) even replicated their priming with the addition of a careful check of attentional switches asking participants to perform a memory task on the attended channel while the prime was played. The authors indicated that two simultaneous messages were more intelligible if their physical properties differed. Rivenez, Darwin, Bourgeon, and Guillaume (2007) also replicated these results using differences in vocal track lengths instead of differences in fundamental frequency between attended and unattended speech.

Therefore, although this question has been heavily debated, it is apparent that unattended speech can indeed be processed when the unattended channel is easily dissociable from the attended channel. Nevertheless, evidence of this phenomenon has only been reported on a repetition-priming paradigm. As repetition priming could be equated to phonological priming, it 
would be interesting to see if individuals can process unattended speech at a semantic level by testing for example whether an unattended word can activate the behavioral pattern with which it is associated.

\section{Priming Motivation Through Unattended Speech}

The purpose of the present research was to examine if a motivational state could be automatically triggered by unattended speech. Second, with regard to motivation priming, it would be very interesting to know if motivation can be primed when attention is distracted, or in other words, when people are inattentive to the primes. Although there is substantial evidence that motivation can be primed in the absence of consciousness, this does not imply that motivation can be primed in the absence of attention. As Koch \& Tsuchiya (2006) have shown, consciousness and attention are clearly distinct processes. They are often confounded because one generally leads to the other : if attention is paid on a stimulus, it increases the chance to be consciously aware of this stimulus. However, if a stimulus is intense, attention is not required for consciousness. In addition, in case of a truly subliminal presentation, a stimulus fails to reach consciousness even when all attentional resources are mobilized (see Dehaene, Changeux, Naccache, Sackur, \& Sergent, 2006). These latter cases clearly illustrate that attention and consciousness are two independent functions. Interestingly, a recent review has tried to disentangle the role of attention and consciousness in motivation (Dijksterhuis, \& Aarts, 2010). Their analysis indicated that motivation would not depend on the level of consciousness but on the level of attention. As such, it would be interesting to know whether or not motivation can be activated without attention. In addition, solving this question would greatly improve knowledge on unattended speech processing by indicating whether or not the unattended speech is processed at a semantic level. 
Two studies were conducted to examine motivation priming through unattended speech. The first study intended to provide a reliable test of this question by using a recent version of the dichotic listening paradigm designed to prevent attentional switches. The second study was carried out to examine whether the activation of motivation through unattended speech has ecological validity. This phenomenon could indeed take place in many common situations as our audition continually detects cues that often stay unattended. Every time auditory cues contain motivationally-related information, they could potentially serve as primes shaping individuals' behavioral response. For example, suppose that you are absorbed in a task while someone nearby speaks passionately about an interesting event he/she just did. Would this kind of situation lead you to suddenly become more committed in doing your current activities? The experimental setting of Study 2 was inspired from this situation to determine ecological validity of such a motivational priming effect.

\section{Study 1}

The purpose of Study 1 was to provide a reliable test of motivation priming through unattended speech. To do so, we used the same dichotic listening procedure as used by Rivenez et al. (2006). Participants were asked to find target words belonging to a specific semantic category in a list of spoken words played in one ear, while ignoring speech played in their other. To prevent attentional switches, words were played at a fast pace in the attended channel and the unattended speech was composed by concatenated, nonsensical sentences instead of isolated words (see Dupoux et al., 2003; Holender, 1986; Rivenez et al., 2006).

Nevertheless, the priming method was quite different from the study by Rivenez et al. (2006). Words related to a high or low intensity of motivation were inserted in some trials in the unattended channel and the priming influence was assessed using a handgrip (dynamometer) 
squeezing task measuring strength exertion. This task has turned to be very sensitive to measure subtle priming of motivational intensity (Aarts et al., 2008; Pessiglione et al., 2007). In comparison to the trials in which no motivation related words were present, it was predicted that participants would react more (less) quickly, and exert more (less) strength to squeeze the handgrip after trials with words related to a high (low, respectively) intensity of motivation.

\section{Method}

\section{Participants and Design}

Thirty undergraduate psychology students (20 females) took part in the experiment for course credits. They were all native English speakers without any reported hearing problems.

\section{Procedure}

When entering into the soundproof room, participants were asked to sit in front of a computer and put on headphones. All instructions were provided on a computer screen, but the experimenter stayed until the end of the practice session to ensure the participants correctly understood them. Participants were asked to only listen to the speech in the right ear, and to ignore the left ear. The practice session was comprised of six trials. At the beginning of each trial, the name of the category was displayed on the screen for 1s, and then the audio would begin. The category name remained on the screen until the end of the trial. Participants were instructed to press a button as fast as possible each time they heard a word belonging to this category (e.g., hearing "golf" when "sport" was displayed). After four trials in the practice

session, participants were informed that they would be asked periodically to squeeze a handgrip after some trials of the test session. Actually, the two last trials of the practice session included the strength exertion measure. Two thousand ms after the offset of the audio sequence, participants were asked to squeeze the handgrip with their dominant hand when the word 
"squeeze" appeared on the screen. They were then asked to squeeze the handgrip as tightly as possible until the word disappeared (2000 ms after its occurrence). Then the participants started the test session. This session included 45 trials divided in 9 blocks. Each block first included three trials followed by the strength measure, and then two trials without the strength measure. Trials were separated by 2000 ms, but no more extra time was provided between blocks. Primes were only inserted in the trials followed by strength measure. The occurrence of the prime words temporally matched the target words in the attended channel. Each block contained primes belonging to one of the three conditions: high, low, or no motivation related words.

\section{Materials}

The list of words of the attended channel was composed by 16 spoken words presented at an average rate of $2( \pm 0.2)$ words per second. In order to avoid attentional switches, there were no gaps between words and we used monosyllabic or quickly pronounced disyllabic words. Words were recorded by a native Canadian English speaker with a monotonous intonation. Eleven semantic categories were used (sport, vegetable, bird, weapon, clothing, fish, fruit, furniture, insect, vehicle, flavor). One or two target words appeared in the list. For the twotargets trials, the second target appeared at the last or second last position in the list.

The unattended messages were composed of nonsensical sentences (e.g., "Witness the tower of that double" "Request the morning from the issue"). Most of the sentences were picked up from Rivenez et al.'s (2006) study, however all of the sentences that included potentially motivational words were eliminated (e.g., "Regard her passion with a temple"). On average, the unattended message included 3.8 sentences (21.6 words) per trial. To avoid attention switches, unattended sentences were recorded without lag in a normal prosody by the same talker. The fundamental frequency was decreased by $40 \mathrm{~Hz}$, and the volume was attenuated by $12 \mathrm{db}$. 
Priming words were naturally embedded at varying positions in the sentences (e.g., "Witness the tower of that great effort"). During each trial of the high and low motivation conditions, two words related to a high or low intensity of motivation were presented. The list of words depicting a state of high intensity of motivation was: "desire, dynamic, effort, alive, energetic, active, joy, enthusiastic, persist, keen, energy, vigorous, performance, vitality, perseverance, improve, motivated, striving", whereas the low motivation words were: "annoying, weak, obligation, tired, asleep, exhausted, lassitude, boring, weariness, constrained, sleepy, useless, obliged, spineless, draining, bother, depleted, resigned".

The unattended speech started $800 \mathrm{~ms}$. after the onset of the attended message with a fade in to help participants focus on the attended speech and ignore the unattended speech. As Rivenez et al. (2006) did not report any influences of laterality on priming effects, all participants were instructed to focus on the channel presented in their right ear and ignore the channel presented in their left ear. The sounds were presented using E-prime software and they were played binaurally via a pair of Audio-Technica ATH900 headphones. Strength exertion was recorded using a Biopac hand dynamometer.

\section{Results and Discussion}

In order to eliminate any possibilities of attention shifts toward the unattended channel, we only kept trials in which the targets words of the attended speech were correctly detected (responses were considered correct when the button was pressed up to $1500 \mathrm{~ms}$ after the occurrence of the target in the audio sequence). As such, $18 \%$ of the trials were removed from the analysis. A general linear model for repeated measures was performed on the total effort exerted by participants on the handgrip-squeezing task (mean force over time). A linear contrast was created to represent our expected pattern of result (low intensity motivation $=-1$; neutral $=$ 
0 ; high intensity motivation $=1)$. This linear contrast significantly predicted total effort $F(1,23)$ $=4.484, p<.05, \eta^{2}=.134$. The Figure 1 illustrates this pattern of results.

This results showed that the presence of low motivation related words in the unattended speech reduced effort, whereas the presence of high motivation related words increased effort in the handgrip-squeezing task. Since effort is closely related to motivational intensity (Brehm, 1989), this study indicates that individuals' motivation can be primed by unattended auditory cues.

Study 2

While Study 1 reliably demonstrated the possibility to prime motivation through unattended speech using a standard dichotic listening setup, Study 2 intended to examine the ecological validity of this phenomenon by using a more realistic setting. As such, while participants focused on a demanding task, they were exposed to the speech of an intrinsically motivated person in the background. The volume of the conversation was determined in a pilot study in order to make it intelligible without attracting participants' attention.

As it has been shown that individuals make automatic inferences about other's motives (Hassin, Aarts, \& Ferguson, 2005), we presumed that participants could extract motivational information from the unattended speech and that, in turn, this information could serve as a prime. In this study, we attempted to prime IM as this general form of motivational orientation is associated with typical cognitive and behavioral outcomes such as greater effort (e.g., Radel et al., 2009b), performance (e.g., Butler, 1988), and persistence (e.g., Sarrazin, Vallerand, Guillet, Pelletier, \& Cury, 2002). In addition, some works showed that IM could be effectively triggered by priming method (e.g., Radel et al., 2009b). 
In this study, the effect of the motivation priming was observed on a word fragment completion task. In order to verify that the priming manipulation was effective, a list of fragments that could be completed with words related to IM was included. We expected that participants primed with IM would have this construct more accessible in working memory (see Higgins, 1996), which would make them more likely to complete these ambiguous fragments with IM related words compared to control participants. Moreover, in order to test whether the unattended conversation had a motivational effect, we monitored participants' performance in completing neutral fragments, and their persistence in completing the last unsolvable fragment. We expected that participants primed with IM would display greater levels of performance to solve the neutral fragments, and a greater persistence before giving up on the unsolvable item than participants in the control group.

\section{Method}

\section{Pilot Study}

Eighteen students were randomly assigned to three conditions of volume attenuation level (i.e., - 35, -38 , and $-41 \mathrm{~dB}$ ). When participants arrived, they sat in front of a computer located at the back of a 5-meter long room. They completed a 9 min. memorization task consisting of 36 trials. Participants first saw an abstract picture and then had to determine whether a second picture was the same or different. Between the two pictures, participants were asked to add or subtract 2-digits numbers. Meanwhile, the same auditory background as used in the experimental condition (see the corresponding section for a full description) was played. At the end, the experimenter interrogated the participants to find out whether or not they had noticed the presence of the auditory background via a funneled debriefing (see Bargh \& Chartrand, 2000; our questions are displayed in the supplemental materials). Moreover, while listening to the 
conversation again without distraction, participants were asked to transcribe as much of the content as possible. They were given the opportunity to pause the soundtrack in order to have enough time to write.

Results concerning awareness of the auditory background showed that two participants detected the background when it was played at the highest volume but no participants detected it when it was played at the two lowest volume settings. Results concerning understanding of the conversation indicated that the rate of understanding decreased exponentially with the level of volume attenuation: only $12 \%$ of the content was transcribed at the lowest volume, $39 \%$ at the middle volume and $52 \%$ at the highest volume. The $-38 \mathrm{~dB}$ attenuation was selected for the main study because no participants noticed the background at this intensity while a substantial part of the content could be understood.

\section{Participants}

Sixty-eight French undergraduate students (35 males and 33 females) participated on a voluntary basis. They were randomly assigned to one of the two groups (IM priming vs. control condition).

\section{Procedure}

In a first time, participants performed the same cognitive task as in the pilot study. Immediately after, participants completed a word fragment completion task (see Roediger, Weldon, Stadler, \& Riegler, 1992), which consists of creating words by adding letters to incomplete words as fast as possible. No constraints on possible completions were imposed, and each fragment had between three and six possible solutions. For seven of the thirteen solvable fragments, participants could find a French word referring to IM (English translations are: urge, pleasure, interest, freedom, volition, joy, desire). None of these words were present in the script 
of the conversation. For the six other words, possible answers were not related to IM. A limited duration of thirty seconds per fragment was set. Another fragment, displayed at the end of the task, had no solution and no time limitation. Participants could therefore continue as long as they wished. Then, the experimenter ran participants through the same funneled debriefing as used in the pilot study in order to examine participants' awareness of the priming. Finally, participants completed a test checking their auditory capacity.

\section{Experimental manipulation}

One minute after the beginning of the memorization task, an auditory background was played slightly above the auditory threshold via an invisible loudspeaker located beside the front door. In agreement with pilot study findings, the original signal was decreased by $38 \mathrm{~dB}$. Following the example of many visual priming experiments that exposed control groups to meaningless stimuli, such as non-words (e.g., Aarts et al., 2005) or abstract pictures (e.g., Gillath, Mikulincer, Birnbaum, \& Shaver, 2008), a conversation was made unintelligible from the beginning to the end using a backward transformation for the control group. This avoided the activation of unwanted constructs that could be primed if meaningful elements were used. At the same time, the general shape and intensity of the signal was preserved; the voice, tone, and pace of the speaker were similar with and without this transformation (Wood \& Cowan, 1995b). For participants in the priming condition, the conversation became intelligible after seven minutes and lasted one more minute. The intelligible part of the conversation was about a male student who told his friend (a female student) about a very interesting activity that he just did (see supplemental materials). This conversation was created in accordance with the definition of IM which postulates that an intrinsically motivated behavior is characterized by enjoyment, discovery and satisfaction (Deci, 1975). 


\section{Dependent Variables}

Accessibility for IM: The number of times participants found the word related to IM in the seven fragments was counted to assess the level of accessibility of the IM construct.

Motivated behaviors: Motivated behaviors displayed during the word fragment completion task were assessed by two performance measures and by a perseverance measure. The performance measures were the total number of correct responses given for the six fragments that could not be filled in with motivation-related words and the average response time for these same words (recorded using the E-prime software). The perseverance measure was indicated by the time spent attempting to solve the unsolvable fragment.

\section{Results and discussion}

Participants' performance on the first task was high ( $\mathrm{M}=76 \% \pm 8 \%$ of correct answers). In order to eliminate possibilities of attention switches during the task, we removed participants who displayed the lowest scores (9 participants below 1 standard deviation to the mean). In addition, two others were eliminated because of minor hearing impairments, so the final sample comprised 28 participants in the IM condition and 29 participants in the control condition. As shown by the responses given in the debriefing, all remaining participants did not detect the prime, suggesting that they did not pay attention to it.

An omnibus test including the measures of IM accessibility, performance and perseverance was first performed to determine the multivariate effect of the priming condition. Results indicated that the priming condition was effective $\left(F(3,53)=2.611, p<.05, \eta^{2}=.167\right)$. Table 1 reports the descriptive statistics and univariate effect for each dependent variable. As one can see, IM accessibility was higher for the priming group than for the control group. In addition, the priming group tended to perform better than the control group as revealed by a marginally 
significant effect on the total neutral fragments completed and a significant effect on the response times for these fragments. Finally, a significant effect was found for perseverance, indicating that participants primed with the IM related conversation persevered longer than control participants.

In sum, not only did the unattended conversation activate its corresponding representation in working memory, but it also shaped participants' motivational state accordingly upon the completion of the subsequent cognitive task. In accordance with other studies (e.g., Lévesque \& Pelletier, 2003; Radel et al., 2009b), primed intrinsic motivation was assimilated, thereby generating the same consequences as if it had been consciously triggered.

\section{General Discussion}

The aim of this paper was to test whether one's motivation could be influenced by unattended speech. In both studies, we provided support for the existence of such an effect. Using a modern version of the dichotic listening, Study 1 demonstrated that participants' strength exertion was affected by the type of words present in the unattended channel. When some words related to a high (low) motivational intensity were embedded in the stream of speech of the unattended channel, participants exerted more (less) strength compared to the strength they exerted when only neutral words were present in the unattended channel. It is interesting to note that this effect is not likely due to attentional switches because we only included trials in which participants were successful at detecting the targets in the attended channel, which required a careful and continuous attention to this channel. In addition, the unattended channel was constituted by low volume continuous speech, known to prevent attracting attention (Dupoux et al., 2003). Study 2 activated another form of motivation, varying not on quantity but on quality. We used Deci's (1975) concept of intrinsic motivation because this form of motivation is capable 
of predicting a wide variety of different outcomes which proved to be meaningful in many different contexts such as education (Reeve, 2009), work (Gagné \& Deci, 2005), or sport (Hagger \& Chatzisarantis, 2007). Using a more realistic priming manipulation in which a barely audible conversation was played while participants were focused on a demanding task requiring all their attention, we observed that the motivational priming also affected participants' behaviors and performance to respond to a subsequent task. Specifically participants primed with a conversation depicting intrinsic motivation performed better and tended to persist longer to solve the items of the cognitive task than those who were only exposed to a similar but unintelligible auditory signal.

The main contribution of our findings pertains to the line of research on automatic processing of motivation. During the last decades, the conventional view assuming that one's motivational state resulted from conscious reflection on the costs and benefits related to a certain situation has been increasingly challenged by many studies reporting motivation priming outside awareness (e.g., Aarts et al., 2008; Bargh et al., 2001). But if it is now well established that motivation can be automatically triggered without consciousness, the fact that motivation could also be automatically triggered when attention is not directed toward the prime was yet to be shown. Our findings filled this gap by showing that motivational primes embedded in the unattended speech could influence motivational response of participants to engage in a subsequent task. As such, our results appear consistent with recent findings showing that some priming effets can be found outside of attention (e.g., Rolke, Heil, Streb, \& Hennighausen 2001). However, our results contrasts to the pivotal role given to attention in motivational processes (Badgaiyan, 2000; Dijksterhuis \& Aarts, 2010). More specifically, Dijksterhuis and Aarts (2010) indicated that if consciousness is not necessary for pursuing goals, attention would 
be essential for this process. If there is a large support for this proposition, the present data suggests that attention would not be strictly necessary, in a first time, to determine the nature of the motivational state. While a specific type of motivation could be activated outside of the attentional focus, we agree on the fact that attention would play a crucial role in a later stage, as attention would come to facilitate goals attainment by orienting individuals toward stimuli relevant to the activated goal (e.g., Aarts, Dijksterhuis, \& De-Vries, 2001; Radel \& ClémentGuillotin, 2012). In addition, if attention is not necessary to activate motivation, it is very likely that attention would modulate the magnitude of the priming effect. As shown by Kiefer \& Brendel (2006), attended stimuli may engender a greater activation than unattended ones. For future studies, it would be interesting to see if the same unattended motivational priming effect could be replicated with a different paradigm, examining for example if visual stimuli displayed in a rapid serial visual presentation task (Raymond, Shapiro, \& Arnell, 1992) can lead to priming effect when they occurred during the attentional blink.

These findings provide an important contribution to the literature on the processing of unattended speech, because they showed a case of semantic priming in conditions that prevented for attentional switches. Although a few other studies have reported semantic processing of unattended stimuli (e.g., Eich, 1984; Moray, 1959), conclusions from these results could be interpreted as a shift of the attentional focus from the attended channel to the unattended channel that could have allowed participants to catch the unattended stimuli as the characteristics of the main task encouraged participants' attention to wander. This is not likely to be the case in our study given the high level of performance in the main task. Nevertheless, since performance on the task of the attended channel is an indirect measure of the locus of attention, it would be interesting for future studies to go a step further and find ways to monitor participants' attention 
online when the prime appeared in the unattended channel. Nevertheless, these findings match well with Groeger's (1988) claim that automatic processing (processing without awareness or without attention) is fully able to extract the meaning of the ongoing inputs. The priming effect observed in our studies indeed required to extract the meaning of all the stimuli because motivation related words were inserted between many other neutral stimuli in the unattended speech.

This kind of motivation priming effect is also likely to have many practical implications. Given that a large amount of the auditory inputs are filtered out because of the limited capacity of higher-level processing, and given that many cues have a motivational relevance, this effect could depict a widespread influence in real life. Study 2 illustrated this effect, showing that individuals' motivation can be vulnerable to external influences when their attention is mobilized elsewhere. It would be interesting to know whether protective mechanisms exist to moderate the occurrence of this effect. For example, it has been shown that mindful individuals are less sensitive to unconscious motivation priming (Radel et al., 2009a). This could also be the case for motivation priming in divided attention. Similarly, motivational states that are either irrelevant to the situation or uncommon could be more difficult to activate. These issues will also deserve further attention in order to determine the importance of this phenomenon in one's life. 


\section{References}

Aarts, H., Chartrand, T. H., Custers, R., Danner, U., Dik, G., Jefferis, V. E., \& Cheng, C. M. (2005). Social stereotypes and automatic goal pursuit. Social Cognition, 23, 465-490.

Aarts, H., Custers, R., \& Marien, H. (2008). Preparing and motivating behavior outside of awareness. Science, 319, 1639.

Aarts, H., Dijksterhuis, A., \& De Vries, D. (2001). On the psychology of drinking: Being thirsty and perceptually ready. British Journal of Psychology, 92, 631-642.

Aarts, H., Gollwitzer, P. M., \& Hassin, R. (2004). Goal contagion: Perceiving is for pursuing. Journal of Personality and Social Psychology, 87, 23-37.

Ajzen, I. (1991). The theory of planned behavior. Organizational Behavior and Human Decision Processes, 50, 179-211.

Badgaiyan, R. D. (2000). Executive control, willed actions, and nonconscious processing. Humain Brain Mapping, 9, 38-41.

Bandura, A. (1986). Social foundations of thought and action: A social cognitive theory. Englewood Cliffs, NJ: Prentice-Hall.

Bargh, J. A. (1994). The four horsemen of automaticity: Awareness, efficiency, intention, and control in social cognition. In R. S. Wyer \& T. K. Srull (Eds.), Handbook of social cognition (pp. 1-40). Hillsdale, NJ: Erlbaum.

Bargh, J., \& Chartrand, T. (2000). The mind in the middle: A practical guide to priming and automaticity research. In H. T. Reis \& C. M. Judd (Eds.), Handbook of research methods in social and personality psychology (pp. 253-285). NY: Cambridge University Press. 
Bargh, J. A., Gollwitzer, P. M., Lee Chai, A., Barndollar, K., \& Trotschel, R. (2001). The automated will: Non-conscious activation and pursuit of behavioral goals. Journal of Personality and Social Psychology, 81, 1014-1027.

Bentin, S., Kutas, M., \& Hillyard, S. A. (1995). Semantic processing and memory for attended and unattended words in dichotic listening: Behavioral and electrophysiological evidence. Journal of Experimental Psychology: Human Perception and Performance, 21, 54-67.

Broadbent, D. E. (1958). Perception and Communication. New York: Pergamon.

Butler, R. (1988). Enhancing and undermining intrinsic motivation: the effects of taskinvolving and ego-involving evaluation on interest and involvement. British Journal of Educational Psychology, 58, 1-14.

Cherry, E. C. (1953). Some experiments on the recognition of speech, with one and two ears. Journal of the Acoustical Society of America, 25, 975-979.

Custers, R., \& Aarts, H. (2010). The unconscious will: How the pursuit of goals operates outside of conscious awareness. Science, 329, 47-50.

Deci, E. L. (1975). Intrinsic motivation. New York: Plenum Press.

Dehaene, S., Changeux, J., Naccache, L., Sackur, J., \& Sergent, C. (2006). Conscious, preconscious, and subliminal processing: A testable taxonomy. Trends in Cognitive Sciences, 10, 204-211.

Deutsch, J. A., \& Deutsch, D. (1963). Attention: some theoretical considerations. Psychological Review, 70, 80-90.

Dijksterhuis, A., \& Aarts, H. (2010). Goals, attention, and (un)consciousness. Annual Review of Psychology, 16, 467-490. 
Dupoux, E., Kouider, S., \& Mehler, J. (2003). Lexical access without attention? Exploration using dichotic priming. Journal of Experimental Psychology: Human Perception and Performance, 29, 172-184.

Eich, E. (1984). Memory for unattended events: Remembering with and without awareness. Memory \& Cognition, 12, 105-111.

Freud, S. (1920/1981). Au-delà du principe de plaisir. Paris: Payot.

Gagné, M., \& Deci, E. L. (2005). Self-determination theory and work motivation. Journal of Organizational Behavior, 26, 331-362.

Gillath, O., Mikulincer, M., Birnbaum, G., \& Shaver, P. R. (2008). When Sex Primes Love: Subliminal Sexual Priming Motivates Relational Goal Pursuit. Personality and Social Psychology Bulletin, 34, 1057-1069.

Groeger, J. A. (1988). Qualitatively different effects of undetected and unindentified auditory primes. Quarterly Journal of Experimental Psychology, 40, 323-339.

Hagger, M. S., \& Chatzisarantis, N. L. (2007). Intrinsic motivation and self-determination in exercise and sport. Champaign, IL: Human Kinetics.

Hassin, R., Aarts, H., \& Ferguson, M. J. (2005). Automatic goal inferences. Journal of Experimental Social Psychology, 41, 129-140.

Higgins, E. T. (1996). Knowledge activation: Accessibility, applicability and salience. In E. T. Higgins \& A. W. Kruglanski (Eds.), Social Psychology: Handbook of basic principles (pp. 133-168). NY: The Guilford Press.

Holland, R. W., Hendriks, M., \& Aarts, H. (2005). Smells like clean spirit. Non-conscious effects of scent on cognition and behavior. Psychological Science, 16, 689-693. 
Kiefer, M., \& Brendel, D. (2006). Attentional modulation of unconscious "automatic" processes: Evidence from event-related potentials in a masked priming paradigm. Journal of Cognitive Neuroscience, 18, 184-198.

Koch, C., \& Tsuchiya, N. (2006). Attention and consciousness: two distinct brain processes. Trends in Cognitive Sciences, 11, 16-22.

Lévesque, C., \& Pelletier, L. G. (2003). On the investigation of primed and chronic autonomous and heteronomous motivational orientation. Personality and Social Psychology Bulletin, 29(12), 1570-1584.

Locke, E. A., \& Latham, G. P. (1990). A theory of goal setting and task performance. Englewood Cliffs, NJ: Prentice Hall.

Macrae, C. N., \& Johnston, L. (1998). Help, I need somebody: Automatic action and inaction. Social Cognition, 16, 400-417.

Maslow, A. H. (1943). A theory of human motivation. Psychological Review, 50, 370-396.

McClelland, D. C. (1985). Human motivation. Glenview, IL: Scott, Foresman.

Mitchell, J. P., Macrae, C. N., Schooler, J. W., Rowe, A. C., \& Milne, A. (2002). Directed remembering: Subliminal cues alter nonconscious memory strategies. Memory \& Cognition, 10, 381-388.

Moray, N. (1959). Attention in dichotic listening: Affective cues and the influence of instructions. Quaterly Journal of Experimental Psychology, 11, 56-60.

Newstead, S. E., \& Dennis, I. (1979). Lexical and grammatical processing of unshadowed messages: a re-examination of the MacKay effect. Quaterly Journal of Experimental Psychology, 31, 477-488. 
Pessiglione, M., Schmidt, L., Draganski, B., Kalisch, R., Lau, H., Dolan, R. J., et al. (2007). How the brain translates money into force: A neuroimaging study of subliminal motivation. Science, 316, 904-906.

Posner, M. I. (1990). The attentional System of the human brain. Annual Review of Neurosciences, 13, 25-42.

Radel, R. Clément-Guillotin, C. (2012). Evidence of motivational influences in early visual perception: Hunger modulates conscious access. Psychological Science. doi:10.1177/0956797611427920

Radel, R., Sarrazin, P., Legrain, P., \& Gobancé, L. (2009a). Subliminal priming of motivational orientation in educational settings: Effect on academic performance moderated by mindfulness. Journal of Research in Personality, 43, 695-698.

Radel, R., Sarrazin, P., \& Pelletier, L. (2009b). Evidence of subliminally primed motivational orientations: The effects of unconscious motivational processes on the performance of a new motor task. Journal of Sport and Exercise Psychology, 31, 657-674.

Raymond, J. E., Shapiro, K. L., \& Arnell , K. M. (1992). Temporary suppression of visual processing in an RSVP task: An attentional blink. Journal of Experimental Psychology: Human Perception and Performance, 18, 849-860.

Reeve, J. (2009). Why teachers adopt a controlling motivating style toward students and how they can become more autonomy supportive. Educational Psychologist, 44, 159-178.

Rivenez, M., Darwin, C. J., Bourgeon, L., \& Guillaume, A. (2007). Unattended speech processing: Effect of vocal-tract length. Journal of the Acoustical Society of America, 121, EL-90-95. 
Rivenez, M., Darwin, C. J., \& Guillaume, A. (2006). Processing unattended speech. Journal of the Acoustical Society of America, 119, 4027-4040.

Roediger, H. L., Weldon, M. S., Stadler, M. L., \& Riegler, G. L. (1992). Direct comparison of two implicit memory tests: Word fragment and word stem completion. Journal of experimental Psychology: Learning, Memory, and Cognition, 18, 1251-1269.

Rolke, B., Heil, M., Streb, J., \& Hennighausen, E. (2001). Missed prime words within the attentional blink evoke an N400 semantic priming effect. Psychophysiology, 38, 165174.

Sarrazin, P., Vallerand, R. J., Guillet, E., Pelletier, L., \& Cury, F. (2002). Motivation and dropout in female handballers: a 21-month prospective study. European Journal of Social Psychology, 32, 395-418.

Shiffrin, R. M., \& Schneider, W. (1977). Controlled and automatic human information processing: II Perceptual learning, automatic attending, and a general theory. Psychological Review, 84, 127-190.

Treisman, A. M. (1964). Selective attention in man. British Medical Bulletin, 20, 12-16.

Wood, N., \& Cowan, N. (1995a). The cocktail party phenomenon revisited: Attention and memory in the classic selective listening procedure of Cherry (1953). Journal of Experimental Psychology: General, 14, 243-262.

Wood, N., \& Cowan, N. (1995b). The cocktail party phenomenon revisited: How frequent are attention shifts to one's own name in an irrelevant auditory channel? Journal of Experimental Psychology: Learning, Memory, and Cognition, 21, 255-260. 
Wood, N., Stadler, M. A., \& Cowan, N. (1997). Is there explicit memory without attention? A reexamination of task demands in Eich's (1984) procedure. Memory \& Cognition, 25, 772779. 
Table 1

Main statistics of the dependent variables according to the priming conditions in Study 2

\begin{tabular}{|c|c|c|c|c|c|}
\hline & \multicolumn{4}{|c|}{ Priming conditions } & \multirow{3}{*}{$t(55)$} \\
\hline & \multicolumn{2}{|c|}{ Priming } & \multicolumn{2}{|c|}{ Control } & \\
\hline & $M$ & $S D$ & $M$ & $S D$ & \\
\hline IM accessibility: Number of IM related words completed & 2.64 & 1.37 & 1.93 & 1.28 & $2.03 *$ \\
\hline Performance 1: Number of neutral fragments completed & 5.61 & 0.57 & 5.26 & 0.80 & $1.86^{\mathrm{t}}$ \\
\hline Performance 2: Mean response time to complete neutral fragments (ms) & 10313 & 2309 & 11799 & 2366 & $-2.40 *$ \\
\hline Perseverance on the unsolvable fragment (ms) & 48455 & 12119 & 42525 & 9980 & $2.02 *$ \\
\hline
\end{tabular}

Notes: ${ }^{\mathrm{t}} p<.07 ; * p<.05$. 


\section{Figures}

Figure 1: Effect of the type of motivation priming on total effort exerted in the squeezing task of Study 1

Note: Error bars represent the standard errors.

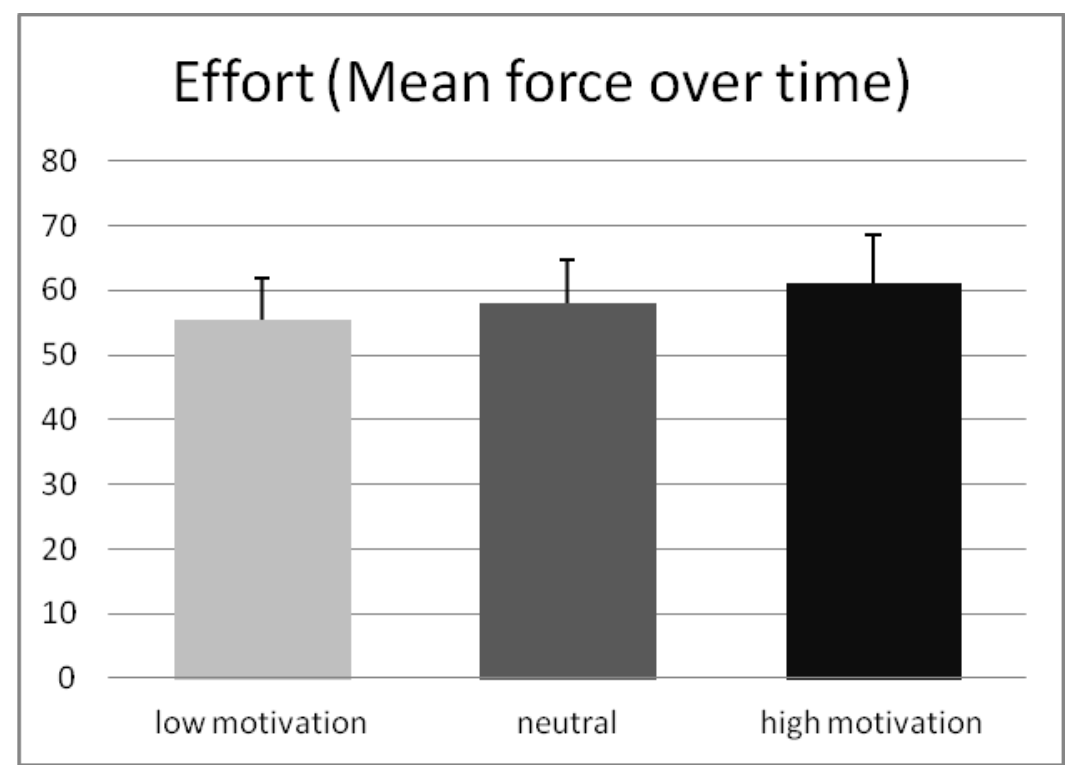




\section{Supplementary Materials}

1. Funneled debriefing concerning the awareness of the stimuli used in Study 2: (translated from French)

- Did you hear a noticeable sound during this task?

- Are you sure that you didn’t hear something that sounded like a conversation?

- Yet, two people were talking in the hall, didn't you notice it?

- Could you tell me, even very broadly, what was the topic of this conversation?

\section{Content of the conversation heard by participants of the priming condition in Study 2:}

(translated from French)

- Male student: ... discovered a great activity I was participating in. Really, it was awesome. I haven't had so much fun in a while.

- Female student: Really, what was it?

- Male student: I don't know how to explain it exactly, but essentially I had to rotate a kind of ball on itself, and as it started to launch, it got really cool because the pressure build-up made the ball rise. Then, it started going faster and faster and let out all this light and a crazy noise kind of like a jet going by. I swear to you, this thing was amazing, it was really great.

- Female student: Really?

- Male student: Yeah, I'm telling you, it's fantastic. And now I absolutely want to get one for my house. I can see it becoming really addictive and wanting to play every day.

- Female student: Did you play long?

- Male student: Well, I'm not really sure. I was so absorbed in it that I think I lost all notion of time. I couldn't tell you if I played 10 minutes or an hour.

- Female student: You make it sound so fun that now I want to try it. 
- Male student: Well, I definitely recommend it. I know that I'll try and find an opportunity to do it again or I might just get one for myself.

- Female student: Ok, I think I'm going to register so that I can try it too. Thanks for telling me about it.

- Male student: You'll see, you'll have so much fun.

- Female student: I'll tell you all about it. Ok I gotta go, I'm going to train. See you later.

- $\quad$ Male student: Ok bye. 